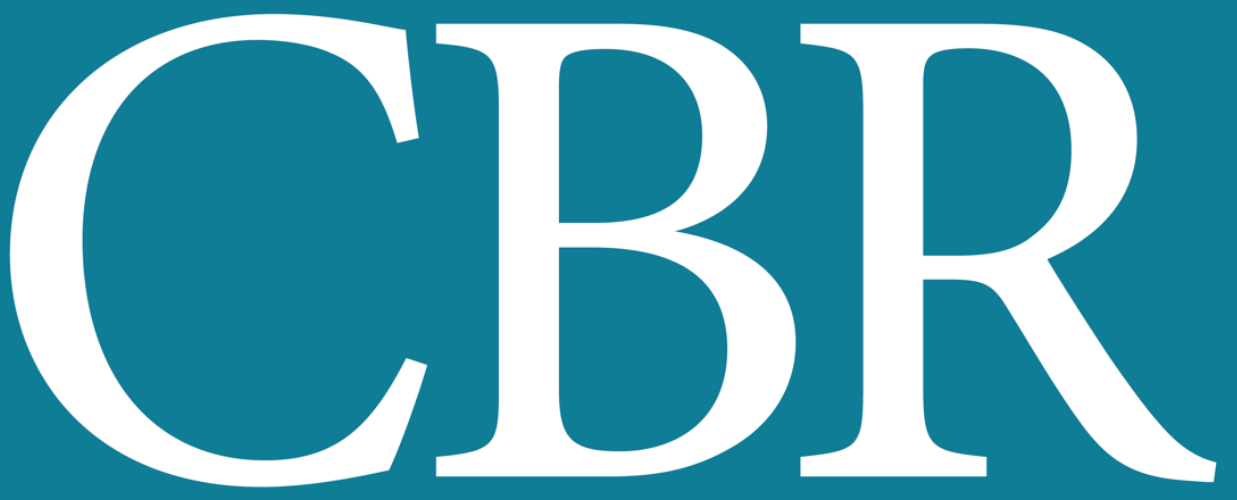

INTERNATIONAL JOURNAL OF CANCER AND BIOMEDICAL RESEARCH

https://jcbr.journals.ekb.eg

Editor-in-chief

Prof. Mohamed Labib Salem, PhD

The Expression of Immune Checkpoint Inhibitors PDL-1 and CTLA-4 in Pancreatic Versus NonPancreatic Periampullary Adenocarcinoma: An Immunohistochemical Study

Noha M. El-Anwar, A. Kamal, Marwa Shabana and Reham S.E. Esmail 


\section{Welcome letter from Editor-in-Chief}

Welcome to the Int J Cancer and Biomedical Research (IJCBR)!

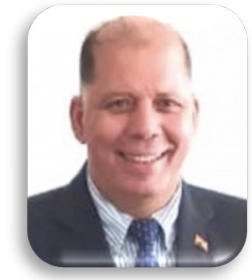

It is with great pleasure that I write this editorial to welcome you to the IJCBR. This journal provides a platform for publication of original and reviews research articles, short communications, letter to editor, thesis abstract, conference report, and case studies. These types of publication are directed at the interface of the fields of cancer and biomedical research.

The IJCBR relies on a distinguished expert of the Advisory and Editorial Board Members from the top international league covering in depth the related topics. They timely review all manuscripts and maintain highest standards of quality and scientific methodology and ethical concepts. Meanwhile, we take all possible means to keep the time of the publication process as short as possible.

I take this chance to welcome your contributions to the IJCBR and have every expectation that it will soon become one of the most respected journals in both the fields of cancer and biomedical research.

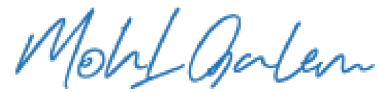

Mohamed L. Salem,

Editor in Chief 


\title{
The Expression of Immune Checkpoint Inhibitors PDL-1 and CTLA-4 in Pancreatic Versus Non-Pancreatic Periampullary Adenocarcinoma: An Immunohistochemical Study
}

\author{
Noha M. El-Anwar ${ }^{1,2}$, A. Kamal ${ }^{3}$, Marwa Shabana ${ }^{4}$ and Reham S.E. Esmail ${ }^{5,2}$ \\ ${ }^{1}$ Department of pathology, Faculty of Medicine, Tanta University, Egypt \\ 2Department of Pathology, Armed Forces College of Medicine, Egypt \\ ${ }^{3}$ Department of Surgical Oncology, National Cancer Institute. \\ ${ }^{4}$ Department of Pathology, National Research Centre. \\ ${ }^{5}$ Department of Pathology, Faculty of Medicine, Fayum University
}

\section{ABSTRACT}

Background: Periampullary cancers constitute about $5 \%$ of gastrointestinal malignancies. They are comprised of tumors of diverse origins and are generally subdivided into pancreatic and non-pancreatic carcinomas. Immune checkpoint regulators, cytotoxic T-lymphocyte antigen 4 (CTLA-4), and the programmed cell death ligand-1 (PDL-1) have emerged as promising new targets for cancer therapeutics. Aim: This study aims to determine the possible role of immune checkpoint inhibitors PDL- 1 and CTLA-4 in periampullary carcinoma of pancreatic and non-pancreatic adenocarcinoma subtypes, in an attempt to investigate the possible introduction of their related immunotherapy in the management of these tumors. Materials and Methods: Expression of immune inhibitory molecules was examined by immunohistochemistry in 40 cases including (20) pancreatic adenocarcinoma and (20) non-pancreatic adenocarcinoma. The association between markers and clinicopathological parameters was evaluated. Results: Statistically significant differences in the immunoexpression of both CTLA-4 and PDL1 in the two studied groups were noticed with higher expression in non-pancreatic adenocarcinoma in relation to pancreatic adenocarcinoma ( $P=0.004, P=0.008)$ respectively. PDL-1 expression was positive in $15 \%$ and $55 \%$ of pancreatic and nonpancreatic adenocarcinoma cases, respectively with a significant correlation with lymph nodes metastasis in non-pancreatic adenocarcinoma cases. CTLA-4 was positive in $20 \%$ of pancreatic carcinoma with a significant correlation with lymph node metastasis, perineural invasion and $\mathrm{T}$ stage. In non-pancreatic periampullary adenocarcinoma, CTLA-4 was positive in $65 \%$ of cases with a significant association with lymph nodes metastasis and T stage. Conclusions: Immunotherapy using antiPDL-1 and CTLA-4 are proposed as a novel promising management tool in nonpancreatic periampullary adenocarcinoma not in pancreatic adenocarcinomas.

Keywords: CTLA-4, non-pancreatic periampullary adenocarcinoma, pancreatic adenocarcinoma, PDL-1

Editor-in-Chief: Prof. M.L. Salem, PhD - Article DOI: 10.21608/jcbr.2021.56525.1108

\section{INTRODUCTION}

Periampullary cancers constitute about $5 \%$ of gastrointestinal malignancies and are classically defined as cancers arising within the distance of $2 \mathrm{~cm}$ of the papilla of Vater. They represent a complex disease entity with divergent heterogenous histogenesis, including pancreatic, ampullary, biliary and duodenal cancers (Bansal et al., 2017). They comprised tumors of diverse origins and generally subdivided into pancreatic (PC) and nonpancreatic carcinomas with the latter having a more favourable prognosis and better overall survival rates (Siegel et al., 2015; Sunil et al., 2017). Histologically, all periampullary cancers are predominantly adenocarcinomas and all are regarded as tumors with the worst prognosis worldwide, with spiky disease-related mortality (Saluja et al., 2019). 
Despite the dynamic progress in both the diagnosis and management, including the newly introduced targeted therapies, surgical resection via pancreaticodoudenectomy (PD) with or without pylorus preservation is still the mainstay of management of periampullary carcinoma as a whole; the role of adjuvant chemotherapy and adjuvant chemoradiation treatment is still questionable and uncertain (Baghmar et al., 2019).

In the last years, the research has approached great achievements in the way to understand the intersection between immune surveillance and tumor initiation and progression, and the concept which has installed novel effective therapeutic tools in many cancer types (Jesus et al., 2018). The overall survival and prognosis of many solid tumors as melanoma, non-small lung carcinoma, and hematologic malignancies have been significantly improved after the introduction of such immunotherapeutic modalities (Kalbasi and Ribas, 2020).

Cytotoxic T-lymphocyte antigen 4 (CTLA-4) is known to be the master of all the immune checkpoint inhibitors, as it prevents T-cell activation at very early initial stages (Buchbinder and Desai, 2016). On the other hand, the programmed cell death protein1/programmed death-ligand 1 PDL-1 acts on the regulation of the previously activated $T$ lymphocytes on later stages of the body immune mechanism (Akinleye and Rasool, 2019). Both CTLA-4 and PDL-1 are responsible for controlling $T$ cell-mediated immune response by "switching off" T-cell effects on the self-cells. Therefore, their blockage will allow for proper stimulation and expression of the immune system against tumor cells (Rapoport et al., 2017).

Both anti-CTLA-4 and anti-PDL- 1 have shown promising results in many gastrointestinal malignancies (Sharma and Allison, 2020), however, some studies have approximated the possible role of immunotherapy in periampullary cancers, with relatively conflicting results and unsteady conclusions (Jiang et al., 2019).

In the current study, we examined the possible role of immune checkpoint inhibitors PDL-1 and CTLA-4 in cases of periampullary carcinoma of pancreatic and non-pancreatic adenocarcinoma subtypes in the management of these tumors by investigating their immunohistochemical expression.

\section{MATERIAL AND METHODS Cases and study groups}

This retrospective multi-center study included 40 cases; 20 cases of pancreatic head adenocarcinoma type and 20 cases of nonpancreatic periampullary adenocarcinoma.

Formalin-fixed paraffin-embedded blocks were collected from archived cases during the last 3 years from Air forces specialized hospital, Naser Institute for treatment and research and Tanta University hospital, according to the following inclusion criteria:

- Availability and integrity of paraffin blocks.

- Full clinicopathological data as illustrated in table 1 including (histopathological diagnosis of adenocarcinoma with no specific variant and precise anatomic location of the tumor).

Cases without a full clinicopathological sheet or bad quality of tissue blocks were excluded. This study was performed in accordance with the Declaration of Helsinki. The evaluation of archived pathology specimens described in the study was approved by the ethical committee of National Research Center (approval code:IRB:6413042020)

The slides were reviewed for:

- Confirmation of the diagnoses

- Reporting the histopathologic findings as perineural invasion and nodal metastasis.

Staging of the tumor was defined according to TNM American Joint Committee on Cancer Union International Center Cancer staging system (AJCC-UICC) (Amin et al., 2017)

\section{Immunohistochemistry methods}

Two unstained slides were cut from the tumor paraffin blocks at 3-5-micron thickness for further immunohistochemical staining for CTLA4 \& PDL-1 according to the following protocol through an automated immunostainer (Ventana BenchMark XT; USA) which runs the following basic steps: Section deparaffinization by xylene, rehydration by graded alcohol then saturation using $0.03 \%$ hydrogen peroxide. This was followed by antigen retrieval by Tris- 
buffered $0.1 \%$ saline and Tween-20 at $\mathrm{pH}=7.6$. Incubation was done with the primary antibodies using PDL-1 antibody (M3653 clone 22C3, Dako, Glostrup, Denmark) and CTLA-4 (Mouse monoclonal antibody, Santa Cruz) at 1:400 dilution for $30 \mathrm{~min}$ at room temperature. The UltraView Universal DAB Detection Kit was used as the secondary antibody in the device. Finally, Samples were counterstained with hematoxylin and mounted in DPX. Sections incubated without the primary antibody were used as negative controls. Tonsil sections were used as a positive control for both PDL-1 and CTLA-4.

\section{Immunohistochemical stains evaluation}

PDL-1 expression was detected as brown membranous staining and CTLA-4 expression was detected as cytoplasmic staining. According to Schlober et al. (2016). In the expression of PDL-1 and CTLA-4 on tumor cells, samples with $>10 \%$ stained tumor cells were considered positive.

\section{Statistical analysis}

Microsoft excel 2013 was used for data entry and the statistical package for social science (SPSS version 24) was used for data analysis. All collected data were revised for competencies and logical consistency. Simple descriptive statistics (arithmetic mean and standard deviation) were used for the summary of normal quantitative data and frequencies used for qualitative data. Bivariate relationship was displayed in cross-tabulations and comparison of proportions was performed using the chisquare and Fisher's exact tests where appropriate. The level of significance was set at a probability $(\mathrm{P})$ value $<0.05$.

\section{RESULTS}

The present study was performed on 40 biopsies; 20 cases of pancreatic adenocarcinoma and 20 cases were nonpancreatic periampullary adenocarcinoma. The studied cases included 23 males and 17 females in the two groups with a mean age of 56 for pancreatic carcinoma cases and 55 for nonpancreatic adenocarcinoma cases with mean standard deviations of 9.434 and 9.691 respectively. The clinicopathological features of the studied cases are summarized in Table 1.
Immunohistochemical of PDL-1 (Figure 1)

PDL-1 expression was detected as brown membranous staining.

Pancreatic adenocarcinoma cases: It was only positive in $3(15 \%)$ of the studied cases. The relations between PDL-1 expression and the studied clinicopathological parameters are summarized in Table 2 . No significant correlation was found with all clinicopathological parameters.

Non-pancreatic adenocarcinoma cases: PDL-1 expression was positive in 11 (55\%) of cases. It was found that PDL-1 expression was significantly correlated with lymph nodes metastasis $(P=0.025)$ as shown in Table 3.

Immunohistochemical of CTLA-4 (Figure 2)

it was detected as cytoplasmic staining. The relation between CTLA-4 and clinicopathological parameters in pancreatic and non-pancreatic adenocarcinoma cases was illustrated in Tables 4 \& 5 .

Pancreatic adenocarcinoma cases: CTLA- 4 was positive in only $4(20 \%)$ of cases, bearing a significant correlation with lymph node metastasis, perineural invasion, and $T$ stage $(\mathrm{P}=0.014, \mathrm{P}=0.025$ and $\mathrm{P}=0.009$ ) respectively.

Non-pancreatic adenocarcinoma cases: CTLA-4 expression was positive in $13(65 \%)$ of cases. It was found that CTLA-4 expression was significantly correlated with lymph nodes metastasis and $T$ stage $(P=0.019, P=0.023)$ respectively.

\section{Correlation of expression of both CTLA-4 and} PDL-1 expression in both groups

There was a significant correlation for higher expression of CTLA-4 and PDL-1 in nonpancreatic adenocarcinoma in relation to pancreatic adenocarcinoma $(P=0.004, P=0.008)$ respectively as illustrated in Table 6 .

\section{DISCUSSION}

Primary adenocarcinomas derived from the head of the pancreas, ampulla, duodenum, or distal bile duct are unitedly referred to as "periampullary" adenocarcinomas (Bakshi et al., 2019). 
Table 1. Clinicopathological features in pancreatic adenocarcinoma and non-pancreatic periampullary adenocarcinoma

\begin{tabular}{|c|c|c|c|c|c|}
\hline & & \multicolumn{4}{|c|}{ Group } \\
\hline & & \multicolumn{2}{|c|}{$\begin{array}{l}\text { Pancreatic } \\
\text { carcinoma }\end{array}$} & \multicolumn{2}{|c|}{$\begin{array}{l}\text { Non-pancreatic } \\
\text { carcinoma }\end{array}$} \\
\hline & & Count & $\%$ & Count & $\%$ \\
\hline \multirow[t]{3}{*}{ Gender } & Male & 13 & $65.0 \%$ & 10 & $50.0 \%$ \\
\hline & Female & 7 & $35.0 \%$ & 10 & $50.0 \%$ \\
\hline & Total & 20 & $100.0 \%$ & 20 & $100.0 \%$ \\
\hline \multirow[t]{3}{*}{ Margin status } & Negative & 12 & $60.0 \%$ & 18 & $90.0 \%$ \\
\hline & Positive & 8 & $40.0 \%$ & 2 & $10.0 \%$ \\
\hline & Total & 20 & $100.0 \%$ & 20 & $100.0 \%$ \\
\hline \multirow[t]{3}{*}{ LN metastasis } & Negative & 12 & $60.0 \%$ & 10 & $50.0 \%$ \\
\hline & Positive & 8 & $40.0 \%$ & 10 & $50.0 \%$ \\
\hline & Total & 20 & $100.0 \%$ & 20 & $100.0 \%$ \\
\hline \multirow[t]{4}{*}{ Differentiation } & Poorly & 4 & $20.0 \%$ & 4 & $20.0 \%$ \\
\hline & Moderately & 9 & $45.0 \%$ & 11 & $55.0 \%$ \\
\hline & Well & 7 & $35.0 \%$ & 5 & $25.0 \%$ \\
\hline & Total & 20 & $100.0 \%$ & 20 & $100.0 \%$ \\
\hline \multirow{3}{*}{$\begin{array}{l}\text { Perineural } \\
\text { invasion }\end{array}$} & Negative & 10 & $50.0 \%$ & 10 & $50.0 \%$ \\
\hline & Positive & 10 & $50.0 \%$ & 10 & $50.0 \%$ \\
\hline & Total & 20 & $100.0 \%$ & 20 & $100.0 \%$ \\
\hline \multirow[t]{5}{*}{ T stage } & $\mathrm{T} 1$ & 10 & $50.0 \%$ & 8 & $40.0 \%$ \\
\hline & $\mathrm{T} 2$ & 6 & $30.0 \%$ & 8 & $40.0 \%$ \\
\hline & T3 & 2 & $10.0 \%$ & 3 & $15.0 \%$ \\
\hline & T4 & 2 & $10.0 \%$ & 1 & $5.0 \%$ \\
\hline & Total & 20 & $100.0 \%$ & 20 & $100.0 \%$ \\
\hline
\end{tabular}

Table 2. Relation between PDL-1 and clinicopathological parameters in pancreatic adenocarcinoma

\begin{tabular}{|c|c|c|c|c|c|c|}
\hline & & \multicolumn{4}{|c|}{ PDL-1 } & \multirow{3}{*}{$P$ value } \\
\hline & & \multicolumn{2}{|c|}{ Negative } & \multicolumn{2}{|c|}{ Positive } & \\
\hline & & Count & $\mathrm{N} \%$ & Count & $\mathrm{N} \%$ & \\
\hline \multirow{3}{*}{ Margin status } & Positive & 7 & $41.2 \%$ & 1 & $33.3 \%$ & \multirow{3}{*}{1.000} \\
\hline & Negative & 10 & $58.8 \%$ & 2 & $66.7 \%$ & \\
\hline & Total & 17 & $100.0 \%$ & 3 & $100.0 \%$ & \\
\hline \multirow{3}{*}{ LN metastasis } & Negative & 11 & $64.7 \%$ & 1 & $33.3 \%$ & \multirow{3}{*}{0.537} \\
\hline & Positive & 6 & $35.3 \%$ & 2 & $66.7 \%$ & \\
\hline & Total & 17 & $100.0 \%$ & 3 & $100.0 \%$ & \\
\hline \multirow{4}{*}{ Differentiation } & Poorly & 3 & $17.6 \%$ & 1 & $33.3 \%$ & \multirow{4}{*}{0.383} \\
\hline & Moderately & 7 & $41.2 \%$ & 2 & $66.7 \%$ & \\
\hline & Well & 7 & $41.2 \%$ & 0 & $0.0 \%$ & \\
\hline & Total & 17 & $100.0 \%$ & 3 & $100.0 \%$ & \\
\hline \multirow{3}{*}{$\begin{array}{l}\text { Perineural } \\
\text { invasion }\end{array}$} & Negative & 10 & $58.8 \%$ & 0 & $0.0 \%$ & \multirow{3}{*}{0.060} \\
\hline & Positive & 7 & $41.2 \%$ & 3 & $100.0 \%$ & \\
\hline & Total & 17 & $100.0 \%$ & 3 & $100.0 \%$ & \\
\hline \multirow{5}{*}{ T stage } & $\mathrm{T} 1$ & 9 & $52.9 \%$ & 1 & $33.3 \%$ & \multirow{5}{*}{0.478} \\
\hline & $\mathrm{T} 2$ & 5 & $29.4 \%$ & 1 & $33.3 \%$ & \\
\hline & T3 & 1 & $5.9 \%$ & 1 & $33.3 \%$ & \\
\hline & T4 & 2 & $11.8 \%$ & 0 & $0.0 \%$ & \\
\hline & Total & 17 & $100.0 \%$ & 3 & $100.0 \%$ & \\
\hline
\end{tabular}


Table 3. Relation between PDL-1 and clinicopathological parameters in non-pancreatic periampullary adenocarcinoma cases

\begin{tabular}{|c|c|c|c|c|c|c|}
\hline & & \multicolumn{4}{|c|}{ PDL-1 } & \multirow{3}{*}{ P value } \\
\hline & & \multicolumn{2}{|c|}{ Negative } & \multicolumn{2}{|c|}{ Positive } & \\
\hline & & Count & $\mathrm{N} \%$ & Count & $\mathrm{N} \%$ & \\
\hline \multirow{3}{*}{ Margins status } & Negative & 8 & $88.9 \%$ & 10 & $90.9 \%$ & \multirow{3}{*}{0.067} \\
\hline & Positive & 1 & $11.1 \%$ & 1 & $9.1 \%$ & \\
\hline & Total & 9 & $100.0 \%$ & 11 & $100.0 \%$ & \\
\hline \multirow{3}{*}{ LN metastasis } & Negative & 7 & $77.8 \%$ & 3 & $27.3 \%$ & \multirow{3}{*}{0.025} \\
\hline & Positive & 2 & $22.2 \%$ & 8 & $72.7 \%$ & \\
\hline & Total & 9 & $100.0 \%$ & 11 & $100.0 \%$ & \\
\hline \multirow{4}{*}{ Differentiation } & Poorly & 0 & $0.0 \%$ & 4 & $36.4 \%$ & \multirow{4}{*}{0.056} \\
\hline & Moderately & 5 & $55.6 \%$ & 6 & $54.5 \%$ & \\
\hline & Well & 4 & $44.4 \%$ & 1 & $9.1 \%$ & \\
\hline & Total & 9 & $100.0 \%$ & 11 & $100.0 \%$ & \\
\hline \multirow{3}{*}{$\begin{array}{l}\text { Perineural } \\
\text { invasion }\end{array}$} & Negative & 6 & $66.7 \%$ & 4 & $36.4 \%$ & \multirow{3}{*}{0.178} \\
\hline & Positive & 3 & $33.3 \%$ & 7 & $63.6 \%$ & \\
\hline & Total & 9 & $100.0 \%$ & 11 & $100.0 \%$ & \\
\hline \multirow{5}{*}{ T stage } & $\mathrm{T} 1$ & 6 & $66.7 \%$ & 2 & $18.2 \%$ & \multirow{5}{*}{0.095} \\
\hline & $\mathrm{T} 2$ & 3 & $33.3 \%$ & 5 & $45.5 \%$ & \\
\hline & T3 & 0 & $0.0 \%$ & 3 & $27.3 \%$ & \\
\hline & T4 & 0 & $0.0 \%$ & 1 & $9.1 \%$ & \\
\hline & Total & 9 & $100.0 \%$ & 11 & $100.0 \%$ & \\
\hline
\end{tabular}

Table 4. Relation between CTLA-4 and clinicopathological parameters in pancreatic adenocarcinoma cases

\begin{tabular}{|c|c|c|c|c|c|c|}
\hline & & \multicolumn{4}{|c|}{ CTLA-4 } & \multirow{3}{*}{$P$ value } \\
\hline & & \multicolumn{2}{|c|}{ Negative } & \multicolumn{2}{|c|}{ Positive } & \\
\hline & & Count & N\% & Count & $\mathrm{N} \%$ & \\
\hline \multirow{3}{*}{ Positive margins } & Positive & 8 & $50.0 \%$ & 0 & $0.0 \%$ & \multirow{3}{*}{0.117} \\
\hline & Negative & 8 & $50.0 \%$ & 4 & $100.0 \%$ & \\
\hline & Total & 16 & $100.0 \%$ & 4 & $100.0 \%$ & \\
\hline \multirow{3}{*}{ LN metastasis } & Negative & 12 & $75.0 \%$ & 0 & $0.0 \%$ & \multirow{3}{*}{0.014} \\
\hline & Positive & 4 & $25.0 \%$ & 4 & $100.0 \%$ & \\
\hline & Total & 16 & $100.0 \%$ & 4 & $100.0 \%$ & \\
\hline \multirow{4}{*}{ differentiation } & Poorly & 2 & $12.5 \%$ & 2 & $50.0 \%$ & \multirow{4}{*}{0.133} \\
\hline & Moderately & 7 & $43.8 \%$ & 2 & $50.0 \%$ & \\
\hline & Well & 7 & $43.8 \%$ & 0 & $0.0 \%$ & \\
\hline & Total & 16 & $100.0 \%$ & 4 & $100.0 \%$ & \\
\hline \multirow{3}{*}{$\begin{array}{l}\text { Perineural } \\
\text { invasion }\end{array}$} & Negative & 10 & $62.5 \%$ & 0 & $0.0 \%$ & \multirow{3}{*}{0.025} \\
\hline & Positive & 6 & $37.5 \%$ & 4 & $100.0 \%$ & \\
\hline & Total & 16 & $100.0 \%$ & 4 & $100.0 \%$ & \\
\hline \multirow{5}{*}{ T stage } & $\mathrm{T} 1$ & 10 & $62.5 \%$ & 0 & $0.0 \%$ & \multirow{5}{*}{0.009} \\
\hline & $\mathrm{T} 2$ & 4 & $25.0 \%$ & 2 & $50.0 \%$ & \\
\hline & T3 & 0 & $0.0 \%$ & 2 & $50.0 \%$ & \\
\hline & T4 & 2 & $12.5 \%$ & 0 & $0.0 \%$ & \\
\hline & Total & 16 & $100.0 \%$ & 4 & $100.0 \%$ & \\
\hline
\end{tabular}


Table 5. Relation between CTLA-4 and clinicopathological parameters in non-pancreatic periampullary adenocarcinoma cases

\begin{tabular}{|c|c|c|c|c|c|c|}
\hline & & \multicolumn{4}{|c|}{ CTLA-4 } & \multirow{3}{*}{$P$ value } \\
\hline & & \multicolumn{2}{|c|}{ Negative } & \multicolumn{2}{|c|}{ Positive } & \\
\hline & & Count & N\% & Count & N\% & \\
\hline \multirow{3}{*}{ Positive margins } & Negative & 6 & $85.7 \%$ & 12 & $92.3 \%$ & \multirow{3}{*}{0.059} \\
\hline & Positive & 1 & $14.3 \%$ & 1 & $7.7 \%$ & \\
\hline & Total & 7 & $100.0 \%$ & 13 & $100.0 \%$ & \\
\hline \multirow{3}{*}{ LN metastasis } & Negative & 6 & $85.7 \%$ & 4 & $30.8 \%$ & \multirow{3}{*}{0.019} \\
\hline & Positive & 1 & $14.3 \%$ & 9 & $69.2 \%$ & \\
\hline & Total & 7 & $100.0 \%$ & 13 & $100.0 \%$ & \\
\hline \multirow{4}{*}{ differentiation } & Poorly & 0 & $0.0 \%$ & 4 & $30.8 \%$ & \multirow{4}{*}{0.171} \\
\hline & Moderately & 4 & $57.1 \%$ & 7 & $53.8 \%$ & \\
\hline & Well & 3 & $42.9 \%$ & 2 & $15.4 \%$ & \\
\hline & Total & 7 & $100.0 \%$ & 13 & $100.0 \%$ & \\
\hline \multirow{3}{*}{$\begin{array}{l}\text { Perineural } \\
\text { invasion }\end{array}$} & Negative & 5 & $71.4 \%$ & 5 & $38.5 \%$ & \multirow{3}{*}{0.350} \\
\hline & Positive & 2 & $28.6 \%$ & 8 & $61.5 \%$ & \\
\hline & Total & 7 & $100.0 \%$ & 13 & $100.0 \%$ & \\
\hline \multirow{5}{*}{ T stage } & $\mathrm{T} 1$ & 6 & $85.7 \%$ & 2 & $15.4 \%$ & \multirow{5}{*}{0.023} \\
\hline & $\mathrm{T} 2$ & 1 & $14.3 \%$ & 7 & $53.8 \%$ & \\
\hline & T3 & 0 & $0.0 \%$ & 3 & $23.1 \%$ & \\
\hline & T4 & 0 & $0.0 \%$ & 1 & $7.7 \%$ & \\
\hline & Total & 7 & $100.0 \%$ & 13 & $100.0 \%$ & \\
\hline
\end{tabular}

The subtyping of periampullary adenocarcinoma into pancreatic and nonpancreatic subtypes appeared to be an important prognostic determination; as the non-pancreatic type has shown to possess better prognosis and overall survival in many studies (Schiergens et al., 2015).

Immune checkpoint regulators, (CTLA-4) and (PDL-1), have recently emerged as promising novel targets for cancer therapeutics, with inspiring results in many solid tumors and leukaemia (Kassardjian et al., 2018). The critical goal of the immune checkpoint therapeutic antibodies is inactivating the immune checkpoint proteins shifting the balance from immune suppression to immune activation (McArthur and Page, 2016). The possible role of immune checkpoint inhibitors in periampullary carcinomas remains obscure.

According to our results, PDL-1 expression was detected in only $(15 \%)$ of PC cases as opposed to statistically significantly higher expression in the non-pancreatic group; which reached up to $55 \%$ of cases $(P=0.008)$. In contrast to our results, Sideras and coworkers showed that many immune inhibitory molecules especially
PDL-1 are expressed by pancreatic and ampullary cancer cells and these molecules can become valuable targets for immunotherapy (Sideras et al, 2017). Their study concluded that cancers arising from the ampulla aren't biologically different from cancers arising from the pancreas. However, their findings couldn't be generalized to a broader definition of periampullary tumors, which include distal cholangiocarcinomas and duodenal adenocarcinoma, which were excluded from their studied cases.

In our cases, the expression of PDL-1 in PC cases showed no significant correlation with any of the studied prognostic clinicopathological parameters. Whilst in non-pancreatic periampullary adenocarcinoma cases, the expression was significantly correlated with positive lymph nodes metastasis (poor prognostic parameter) $(\mathrm{P}=0.025)$.

Conspicuous variation in the results of PDL-1 expression in periampullary carcinoma as well as other cancers was observed; the reported expression of PDL-1 in tumor cells of PC in different studies ranged from 12 up to $90 \%$ (Soares et al., 2015; Lu et al., 2017). 
Table 6. Correlation between PDL-1 and CTLA-4 immunohistochemical expression in both groups

\begin{tabular}{|c|c|c|c|c|c|c|}
\hline & & \multicolumn{4}{|c|}{ Group } & \multirow{3}{*}{$P$ value } \\
\hline & & \multicolumn{2}{|c|}{ Pancreatic Carcinoma } & \multicolumn{2}{|c|}{ Non-pancreatic carcinoma } & \\
\hline & & Count & $\%$ & Count & $\%$ & \\
\hline \multirow{3}{*}{ PDL1 } & Negative & 17 & $85.0 \%$ & 9 & $45.0 \%$ & \multirow{3}{*}{0.008} \\
\hline & Positive & 3 & $15.0 \%$ & 11 & $55.0 \%$ & \\
\hline & Total & 20 & $100.0 \%$ & 20 & $100.0 \%$ & \\
\hline \multirow{3}{*}{ CTLA4 } & Negative & 16 & $80.0 \%$ & 7 & $35.0 \%$ & \multirow{3}{*}{0.004} \\
\hline & Positive & 4 & $20.0 \%$ & 13 & $65.0 \%$ & \\
\hline & Total & 20 & $100.0 \%$ & 20 & $100.0 \%$ & \\
\hline
\end{tabular}
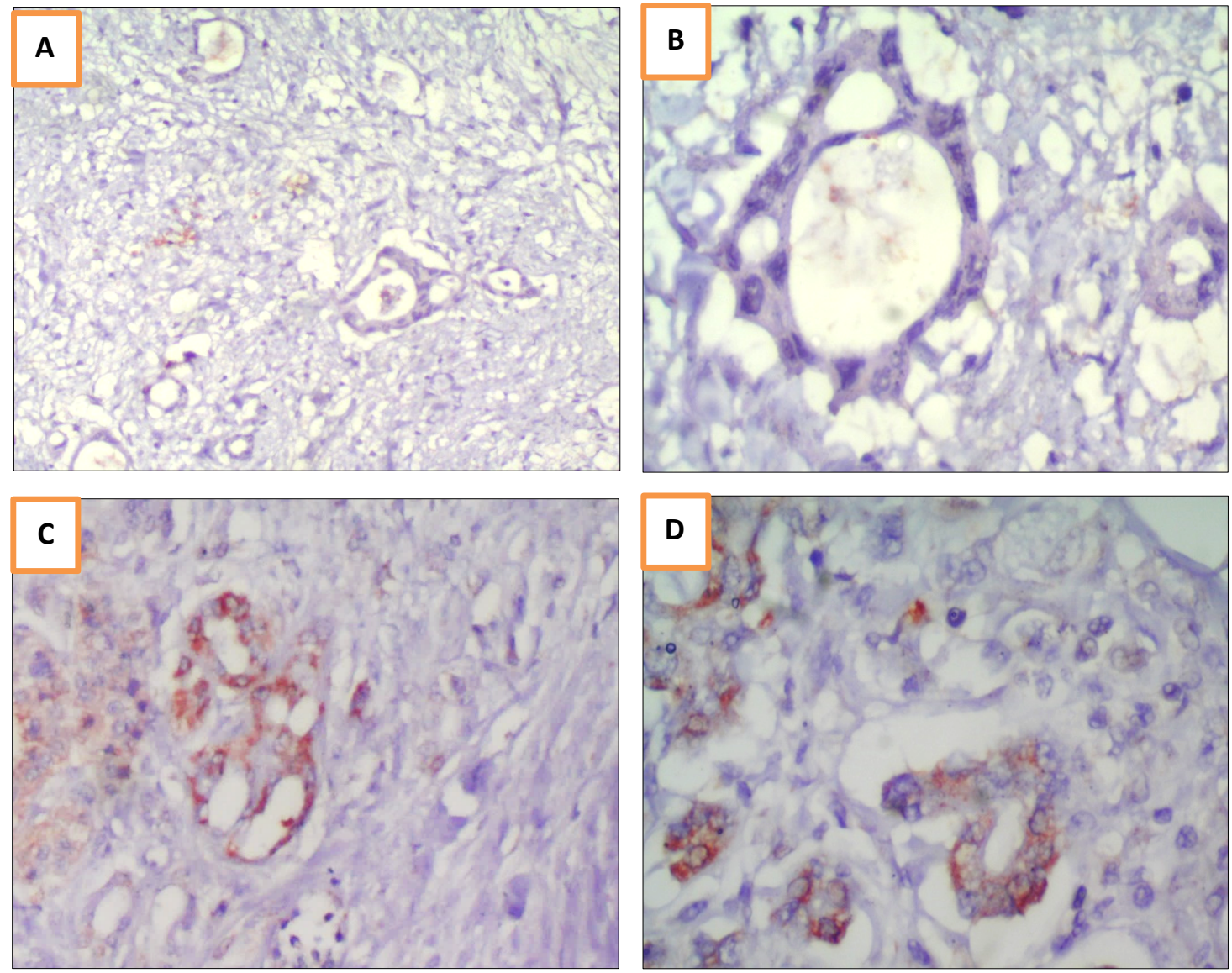

Figure 1. PDL-1 immunohistochemical expression in the cases: A \& B - Pancreatic adenocarcinoma with a negative expression for Pdl1 Low and high power (x200, x400). C \& D - Non-pancreatic periampullary adenocarcinoma showed positive membranous expression of PDL-1 low and high power ( $x 200, x 400)$.

The possible most accepted explanation for this variation is the probable use of different antibodies of different PDL-1 clones, as well as the use of divergent positivity scoring systems in interpreting the obtained results. Moreover, some studies focused on PDL-1 expression in tumor cells only, while others calculated its expression in immune cells or stromal cells as part of their scoring parameters (Wang et al. 2010). In agreement with our results, Birnbaum et al. (2016) examined PDL-1 mRNA expression in PC and noticed that only $19 \%$ of their PC cases expressed PDL-1 and that the expression was related to worse survival rates. Nomi et al. (2007) got higher PDL-1 expression reaching $39.2 \%$ of their studied PC cases, however, they stated as well, that the expression was associated with poor prognostic parameters. They, therefore, concluded that PDL1 may be introduced as a novel prognostic marker for human pancreatic cancer and that targeting PDL-1/ PD-1, especially in combination with standard chemotherapy, may exhibit significant therapeutic repercussion. 

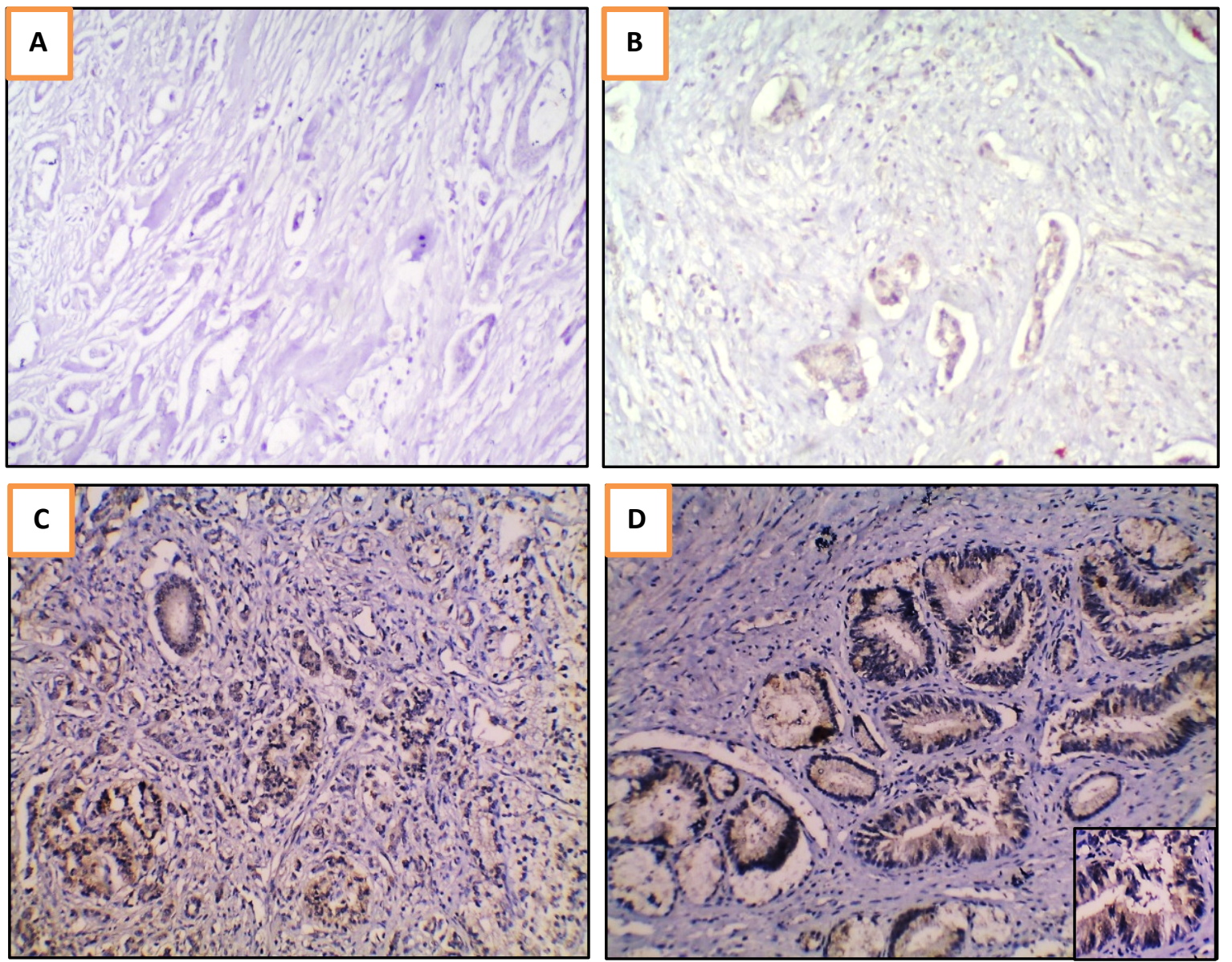

Figure 2. CTLA-4 immunohistochemical expression in the cases: A \& B - Pancreatic adenocarcinoma with a negative expression for CTLA-4 (x200). C - Positive cytoplasmic expression of CTLA-4 in a case of non-pancreatic periampullary adenocarcinoma (x100). D - Another case of non-pancreatic periampullary adenocarcinoma with positive expression of CTLA-4, with inset picture showing cytoplasmic staining $(x 200)$.

On the other hand, Sideras et al. (2017) studied PDL-1 expression on PC and ampullary adenocarcinomas and related its expression with better cancer-specific survival. Compared with colorectal carcinoma, other studies reported that high PDL-1 expression in tumor cells of colorectal carcinoma is significantly associated with nodal and distant metastases (Zhu et al., 2015) as well as with poor differentiation, infiltrating growth pattern and increased lymphovascular invasion (Kim et al., 2016). In our cases, CTLA-4 expression was detected in only $20 \%$ of PC cases contrasted with $65 \%$ in non-pancreatic periampullary adenocarcinoma cases, and the difference was statistically significant $(P=0.004)$. CTL4 expression in PC demonstrated a significant correlation with poor prognostic factors as positive lymph node metastasis $(P=0.014)$, presence of perineural invasion $(P=0.025)$, and advanced tumor stage $(P=0.009)$.
In non-pancreatic periampullary adenocarcinoma cases, significant correlation was shown with positive lymph nodes metastasis $(P=0.019)$ and advanced tumor stage $(P=0.023)$ as well.

To the best of our knowledge, until this time, no other studies examined CTLA-4 expression in pancreatic versus non-pancreatic periampullary adenocarcinoma. Various studies showed that CTLA-4 expression in many tumors was associated with poor prognostic histopathological parameters. Karpathiou et al. (2020) showed that high CTLA-4 tumor cell expression in carcinoma of the uterine cervix was also associated with advanced tumor stage and positive lymph nodes metastasis.

Contrastingly, a study carried out by Schlober et al. (2016) on gastric adenocarcinoma revealed that CTLA-4 was expressed in $86 \%$ of cases with no significant association with lymph nodes metastasis. 
Thus, our study pointed out that the expression of both immune checkpoint inhibitors CTLA-4 and PDL-1 was ultimately significantly higher in non-pancreatic periampullary adenocarcinoma cases in relation to pancreatic adenocarcinoma $(P=0.004, P=0.008)$ respectively, the fact that may be attributed to the confessed nature of PC stroma which is known to be dense, highly desmoplastic, with poor microenvironment and scanty immune cells niche, which make the intra-tumoral stroma generally immunosuppressive (Mahmood et al., 2018).

The above results give new evidence supporting the established concept of the better overall prognosis in non-pancreatic periampullary carcinoma compared to $\mathrm{PC}$, therefore, the segregation between the two tumor types is becoming essential.

While our study provides information on the immunologic profile of pancreatic adenocarcinoma and non-pancreatic periampullary carcinoma, further work is needed to immunologically characterize all different subtypes of periampullary cancer, to illustrate any possible differences within this group. We speculate that the immunological features in periampullary carcinoma may help to guide immunotherapeutic strategies in the future.

\section{CONCLUSIONS}

The study concluded that high expression of PDL-1 and CTLA-4 in non-pancreatic periampullary adenocarcinoma could provide a novel promising management tool of immunotherapy in these tumors, not in the pancreatic adenocarcinomas. Therefore, the differentiation between the two groups is recommended with further large-scale studies to immunologically characterize all different subtypes of periampullary cancer. Besides, our results figured out that the expression of both PDL-1 and CTLA- 4 in non-pancreatic periampullary carcinomas; maybe a poor prognostic parameter.

\section{CONFLICTS OF INTEREST}

All authors declared no conflicts of interest.

\section{FUND}

No fund was received for this work.

\section{REFERENCES}

Akinleye A, Rasool Z (2019). Immune checkpoint inhibitors of PD-L1 as cancer therapeutics. Journal of Hematology \& Oncology, 12: 92-105.

Amin, MB, Greene FL., Edge SB, Compton CC, Gershenwald JE, Brookland RK and Winchester DP (2017). The eighth edition AJCC cancer staging manual: continuing to build a bridge from a population-based to a more "personalized" approach to cancer staging. CA: a cancer journal for clinicians, 67: 93-99.

Baghmar S, Agrawal N, Kumar G, Bihari C, Patidar Y, Kumar S, Chattopadhyay $T$, Panda D, Arora A, Pamecha V (2019). Prognostic Factors and the Role of Adjuvant Treatment in Periampullary Carcinoma: a Single-Centre Experience of 95 Patients. Journal of Gastrointestinal Cancer. 50:361-369.

Bakshi N, Dhawan S, Nundy S, Rao S, Chopra P, Bhalla $S$ (2019). Role of Immunohistochemistry in the Subtyping of Periampullary Adenocarcinoma. International journal of surgical pathology, 27: 598-608.

Bansal A, Dalal V, Kaur M, Siraj F (2017). Periampullary Carcinoma: Unusual Sites of Metastasis. Ochsner Journal, 17 (4) 426-429.

Birnbaum, DJ, Finetti P, Lopresti A, Gilaber, M, Poizat F, Turrini O, Mamessier E. (2016). Prognostic value of PDL1 expression in pancreatic cancer. Oncotarget, 7: 71198- 71210..

Buchbinder E and Desai A (2016). CTLA-4 and PD-1 pathways similarities, differences, and implications of their inhibition. American Journal of Clinical Oncology, 39: 98-106.

Jesus VHFD, Felismino TC, Barros e Silva MJD, Souza e Silva VD, Riechelmann RP (2018). Current approaches to immunotherapy in noncolorectal gastrointestinal malignancies. Clinics, 73 (Suppl. 1), e510s.

Jiang $P$, Zhou $H, N i C$, Hu X, Mou Y, Huang D, Yang L (2019). Immunotherapy in pancreatic cancer: New hope or mission impossible?. Cancer Letters 445, 31: 57-64.

Kalbasi, A and Ribas A (2020). Tumour-intrinsic resistance to immune checkpoint blockade. NatureReviews Immunology 20: 25-39.

Karpathiou G, Chauleur C, Mobarki M, Peoc'h M. (2020). The immune checkpoints CTLA-4 and PD-L1 in carcinomas of the uterine cervix. Pathology-Research and Practice, 216: 152782.

Kassardjian A, Shintaku PI, Moatamed NA (2018). Expression of immune checkpoint regulators, cytotoxic T lymphocyte antigen 4 (CTLA-4) and programmed death-ligand 1 (PD-L1), in female breast carcinomas. PloS one, 13: e0195958.

Kim JH, Park HE, Cho NY, Lee HS and Kang GH (2016). 
Characterisation of PD-L1-positive subsets of microsatellite-unstable colorectal cancers. British journal of cancer, 115: 490-496.

Lu C, Paschall AV, Shi H, Savage N, Waller JL, Sabbatini ME, Liu K. (2017). The MLL1H3K4me3 axis-mediated PD-L1 expression and pancreatic cancer immune evasion. JNCl: journal of the National Cancer Institute, 109 (6): 283-295.

Mahmood J, Shukla HD, Soman S, Samanta S, Singh P, Kamlapurkar S \& Vujaskovic Z (2018). Immunotherapy, radiotherapy, and hyperthermia: A combined therapeutic approach in pancreatic cancer treatment. Cancers, 10: 469-484.

McArthur HL and Page DB (2016). Immunotherapy for the treatment of breast cancer: checkpoint blockade, cancer vaccines, and future directions in combination immunotherapy. Clinical Advances in Hematology \& Oncology, 14:922-933.

Nomi T, Sho M, Akahori T, Hamada K, Kubo A, Kanehiro $H$ and Nakajima $Y$ (2007). Clinical significance and therapeutic potential of the programmed death-1 ligand/programmed death-1 pathway in human pancreatic cancer. Clinical cancer research, 13: 2151-2157.

Rapoport BL, Van Eeden R, Sibaud V, Epstein JB, Klastersky J, Aapro M, Moodley D (2017). Supportive care for patients undergoing immunotherapy. Support Care Cancer 25, 3017-3030.

Saluja SS, Kiran S, Mishra PK, Ramaswamy D, Varshney VK, Godhi S, Sisodia K (2019). LongTerm Functional Outcome After Pancreatoduodenectomy for Periampullary Carcinoma with Morphological Correlation. Pancreas, 48:1182-1187

Schiergens TS, Reu S, Neumann J, Renz BW, Niess H, Boeck S and Kleespies A (2015). Histomorphologic and molecular phenotypes predict gemcitabine response and overall survival in adenocarcinoma of the ampulla of Vater. Surgery, 158:151-161.

Schlößer HA, Drebber $U$, Kloth $M$, Thelen $M$,
Rothschild SI, Haase S, Alakus H. (2016). Immune checkpoints programmed death 1 ligand 1 and cytotoxic T lymphocyte associated molecule 4 in gastric adenocarcinoma. Oncoimmunology, 5: e1100789.

Sharma $P$ and Allison JP (2020). Dissecting the mechanisms of immune checkpoint therapy. Nat Rev Immunol, 20: 75-76.

Sideras, K, Biermann K, Yap K, Mancham S, Boor PP, Hansen BE, Kwekkeboom J (2017). Tumor cell expression of immune inhibitory molecules and tumor-infiltrating lymphocyte count predict cancer-specific survival in pancreatic and ampullary cancer. International journal of cancer, 141: 572-582.

Siegel RL, Miller KD, Jemal A (2015). Cancer statistics. CA: Cancer Journal for Clinicians, 65: 5-29

Soares KC, Rucki AA, Wu AA, Olino K, Xiao Q, Chai Y, Yao S (2015). PD-1/PD-L1 blockade together with vaccine therapy facilitates effector $T$ cell infiltration into pancreatic tumors. Journal of immunotherapy (Hagerstown, Md.: 1997), 38: 1-11.

Spranger S, Spaapen RM, Zha Y, Williams J, Meng Y, Ha TT, Gajewski TF. (2013). Up-regulation of PD-L1, IDO, and Tregs in the melanoma tumor microenvironment is driven by CD8+ T cells. Science translational medicine, 5: 200ra116200 ra116.

Sunil B J, Seshadri R A, Gouthaman S, Ranganathan R (2017). Long-Term Outcomes and Prognostic Factorsin Periampullary Carcinoma. Journal of Gastrointestinal Cancer, 48:13-19.

Wang L, Ma Q, Chen X, Guo K, Li J, Zhang M (2010). Clinical significance of $\mathrm{B} 7-\mathrm{H} 1$ and $\mathrm{B} 7-1$ expressions in pancreatic carcinoma. World journal of surgery, 34: 1059-1065.

Zhu H, Qin H, Huang Z, Li S, Zhu X, He J, Yang J, Yu X, Yi X (2015). Clinical significance of programmed death ligand-1 (PD-L1) in colorectal serrated adenocarcinoma. International journal of clinical and experimental pathology, 8: 93519359. 


\section{Egyptian Association for Cancer Research (EACR)}

http://eacr.tanta.edu.eg/

EACR is an NGO society that was declared by the Ministry of Social Solidarity (Egypt) No. 1938 in 19/11/2014 based on the initiative of Prof. Mohamed Labib Salem, the current Chairman of EACR. EACR aims primarily to assist researchers, in particular young researchers in the field of cancer research through workshops, seminars and conferences. Its first international annual conference entitled "Anti-Cancer Drug Discovery" was successfully organized in April 2019 (http://acdd.tanta.edu.eg). Additionally, EACR aims to raise the awareness of the society about the importance of scientific research in the field of cancer research in prediction, early diagnosis and treatment of cancer. EACR is also keen to outreach the scientific community with periodicals and news on cancer research including peer-reviewed scientific journals for the publication of cutting-edge research. The official scientific journal of EACR is "International Journal of Cancer and biomedical Research (IJCBR: https://jcbr.journals.ekb.eg) was successfully issued in 2017 and has been sponsored by the Egyptian Knowledge Bank (EKB: www.ekb.eg).

\section{EACR Chairman,}

Prof. Mohamed Labib Salem, PhD

Professor of Immunology

Faculty of Science, Tanta Universiy, Egypt 


\section{GUIDE FOR AUTHORS}

Publisher :The International Journal of Cancer and Biomedical Research (IJCBR) is an International and interdisciplinary journal of preclinical and clinical studies in the area of cancer and biomedical research. It is a peer-reviewed journal in English, published quarterly (in March, June, September, and December) by the Egyptian Association for Cancer Research (EACR) in both print and online formats (4 issues making a volume). Special issues or supplements may also be produced from time to time upon agreement with the Editorial Board.

Scope :The main aim of IJCBR is to attract the best research in animal and human biology in health and diseases from across the spectrum of the biomedical sciences at the molecular, cellular, organ, and whole animal levels especially those that are related to cancer research, including causes, prediction, diagnosis, prognosis, and therapy.

Publication Fees :The journal does charge for submission, processing, or publication of manuscripts (2000 LE for Egyptians or $250 \$$ for non-Egyptians; EACR members receive 15\% discount on publication). Of them Peer-review fees (300 LE) should be paid on submission (non-refundable). For the fast-track production of the accepted manuscript, another 500 LE is paid.

General specifications for different types of article

- Submitted manuscripts should not have been published previously, except in a limited form (e.g. short communication to a symposium or as part of MSc or PhD theses) and should not be under consideration for publication by other journals.

- All co-authors should agree with the content of the manuscript. Authors must have obtained permission to use any copyrighted material in the manuscript before submission.

IJCBR publishes different types of articles

- Original Article (6000 words with $\mathbf{4}$ tables and $\mathbf{4}$ figures, maximum $\mathbf{8}$ display items): Articles with novel findings are the target of IJCBR. Articles presenting a detailed description of a new technique, comparison of existing methods, meta-analyses with comprehensive and in-depth discussion are considered. Papers in a numbered series are not accepted unless all are submitted at the same time.

- Short communications or case study (3000 words with $\mathbf{4}$ display items): Short communications present exceptionally exciting, novel or timely contents are considered. They will be peer-reviewed in the same way as research papers. The references are restricted to 15 .

- Reviews or systematic review (9000 words with $\mathbf{1 0}$ display items): They are invited by the Editorial Board or unsolicited. Review articles have to be contemporary and comprehensive and add information to the knowledge. Sharp critical analyses of novel data or concepts are encouraged. When relevant, a statistical analysis of data and a meta-analysis approach are recommended.

- Opinion papers, letter to the editor or comment to the editor (1500 words with $\mathbf{2}$ display items): They are submitted by invitation of the Editorial Board. They are short papers, which aim to inform scientists, industry, and the public and policymakers about cutting-edge issues in research or the impact of research. They reflect the opinion of their authors who bear full responsibility of the published paper. The references are restricted to 10 .

- Conference/Symposium papers: The journal will consider for publication the results of original work and critical reviews that are presented at conferences/symposia. Symposium organizers who wish to publish bundles of papers from a symposium/conference in IJCBR should first contact the Editor-in-Chief of the IJCBR (EACR@unv.tanta.edu.eg) for agreement. Supplementary material can be proposed and will be made available online. The responsibility for the preparation of a paper in a form suitable for publication lies with the author.

- Thesis: IJCBR can publish the summary and abstract of Master and PhD theses in a special issue.

English: Good quality of written English is required. Spelling may be in British or American English but must be consistent throughout the paper. Care should be exercised in the use of biological terminology that is ill-defined or of local familiarity only. We recommend that authors have their manuscripts checked by an English language native speaker before submission.

Manuscript layout: Manuscripts should be prepared using a standard word processing program and presented in a clear readable format with easily identified sections and headings. The manuscript layout is based on the following directions.

- The main text contains Title, Abstract, Keywords, Introduction, Material and Methods, Results, Discussion, References, Tables, figures.

- The title needs to be concise and informative. Use bold, with an initial capital for the first word only and for words that ordinarily take capitals.

- Short (running) title (max 80 characters including spacing).

- The article text should be typed with double line spacing with wide margins $(2.5 \mathrm{~cm})$.

- The lines must be continuously numbered; the pages must also be numbered.

- Font Calibri 12 should be used for the text, and 12 for the tables, figure legends and references.

- The sections should typically be assembled in the following order:

- Title page contains title, authors' names, full affiliations, acknowledgements and the corresponding author's contacts and Short title.

Abstract (max 250 words, single paragraph): The abstract should be complete and understandable without citation, references, table, or figure. Use structured abstract: Background, Aim, Materials \& Methods, Results and Conclusion. The context and the rationale of the study are presented succinctly to support the objectives. The experimental methods and main results are summarized but should not be overburdened by numerical values or probability values. The abstract ends with a short and clear conclusion. 
Keywords: Up to five short and specific keywords should complement the title with respect to indicating the subject of the paper in alphabetic order.

Introduction: The introduction briefly outlines the context of the work, presents the current issues that the authors are addressing and the rationale to support the objectives, and clearly defines the objectives.

Material and methods: Material and methods should be described in sufficient details so that others can repeat the experiment. Reference to previously published work may be used to give methodological details, provided that said publications are readily accessible and in English. The code of ethics should be followed for all experiments use animals or human samples.

Statistical analysis of results: The statistical design and the models of statistical analysis must be described, as well as each of the statistical methods used. Sufficient statistical details must be given to allow replication of the statistical analysis. The experimental unit should be defined (e.g., individual or group of animals).

Results: Data are presented as tables and figures. Brief description of the results for each table and figure should be presented. Unpublished data can be mentioned when necessary.

Discussion: Should be separate from the Results section and should focus only on intra- and inter-data discussion (the data in the results section) as well as with the relative data in the literature. Don't repeat information already presented in the Introduction section. Start the first paragraph in the Discussion with a paragraph stating the rationale behind the study, the objectives, and the main findings. End Discussion with a short conclusion.

Acknowledgements: In this section, the authors may acknowledge (briefly) their support staff.

Conflict of interest: All papers with a potential conflict of interest must include a description/explanation in a separate heading.

Funding details: The authors should state the source of findings of the study (with research funder and/or grant number). If no fund, the authors should state that the study is self-funded.

\section{References}

Citation of references: In the text, references should be cited by the author(s) surname(s) and the year of publication (e.g. Salem, 2020). References with two authors should be cited with both surnames (e.g. Salem and Meshrif, 2021). References with three or more authors should be cited with the first author followed by et al. (in italics; e.g. Salem et al., 2021). Names of organizations used as authors (e.g. Food and Drug Administration) should be written out in full in the list of references and on the first mention in the text. Subsequent mentions may be abbreviated (e.g. FDA).

- List of references. Literature cited should be listed in alphabetical order by authors' names. It is the author's responsibility to ensure that all references are correct. All authors should be written and so the full journal name.

- $\quad$ References from journal articles are formatted in APA as this example: Al-Amoudi WM (2018). Toxic effects of Lambdacyhalothrin on the rat thyroid. Involvement of oxidative stress and ameliorative effect of ginger extract. Toxicology Reports, 5: 728-736.

- $\quad$ References from books or official reports are formatted as this example. Kebreab E, Dijkstra ANM, Bannink A, Gerrits WJJ, \& France J (2006). Nutrient digestion and utilization in farm animals. CABI Publishing. Wallingford, UK.

- References from chapters or parts of books are formatted as this example. Nozière $P, \&$ Hoch $T$ (2006). Modelling fluxes of volatile fatty acids from rumen to portal blood. In: Nutrient digestion and utilization in farm animals (Kebreab E, Dijkstra ANM, Bannink A, Gerrits WJJ \& France J, eds.), pp. 40-47. CABI Publishing. Wallingford, UK.

Tables: The data should be presented in tables or in graphs, not both.

- Each table should be placed on a separate page at the end of the main text.

- Tables are numbered consecutively using Arabic numbering. They are referred to as Table 1 , Table 2, etc., with capital ' $T$ ', no italics

- $\quad$ Each table has its explanatory caption. The caption is sufficient to permit the table to be understood without reference to the text.

- Abbreviations used in tables/figures have to be defined either as footnotes or in the caption.

\section{Figures}

- $\quad$ Package the figures in a single PowerPoint file. Each figure in a separate slide.

- Figure size should be readable in a width of approximately 8-175 $\mathrm{mm}$ (i.e. the maximum size of printing over two columns).

- Ensure that the font size is large enough to be readable at the final print size, use Calibri font to ensure that they are consistent throughout the figures.

- $\quad$ The figures should preferably be provided as TIFF or EPS files.

- The resolutions of figures must be at least $300 \mathrm{dpi}$.

- Preparation of images for a manuscript: For guidance, we refer to the Journal of Cell Biology's instructions to authors (http://jcb.rupress.org/site/misc/ifora.xhtml\#image_aquisition).

- If a cropped image is included in the main text of a paper (e.g. a few lanes of a gel), display the full original image, including the appropriate controls, the molecular size ladder and/or the scale as relevant, as a single figure in a Supplementary Material file to facilitate peer-review and for subsequent online publication.

- Supplementary material is submitted along with the main manuscript in a separate file and identified at uploading as "Supplementary File - for Online Publication Only" The title of the article is included at the top of the supplementary material.

Corresponding author's guidelines: Upon acceptance the corresponding author is required to send his/her recent formal photo to be attached to the front page of the article. 


\title{
International Journal of Cancer \& Biomedical Research
}

(IJCBR) Online ISSN 2682-2628

\author{
Editor-in-Chief \\ Mohamed Labib Salem, PhD \\ Tanta University, Egypt
}

\begin{tabular}{l} 
EACR Board \\
\hline Nehal Elmashad, MD \\
Tanta University, Egypt \\
Nabil Mohy Eldin, PhD \\
Kafrelsheikh University, Egypt \\
Doaa Al-Ghareeb, PhD \\
Alexandria University, Egypt \\
Abdel-Aziz Zidan, PhD \\
Damanhour University, Egypt
\end{tabular}

\begin{tabular}{l} 
Managing Editor \\
\hline Wesam Meshrif, PhD \\
Tanta University, Egypt \\
Sohaila Galal, PhD \\
Tanta University, Egypt \\
Production and Contact \\
\hline Hamdi Kandil \\
Tanta University, Egypt \\
Email: ljcbr100@gmail.com
\end{tabular}

\section{Advisory Board}

Alberto Montero, MD

Taussig Cancer Center, Cleveland,

USA

Yi Zhang, MD

Zhengzhou University, China

Mark Robunstein, Ph D

Medical University of South

Carolina, USA

Mohsen Farid, Ph D

Derby University, USA

Natarajan Muthusamy, Ph D

Ohio State University, USA

Hideki Kasuya, MD

Nagoya University, Japan

Sherif El-Khamisy, Ph D

Sheffield University, UK

Mohamed Ghanem, Ph D

Kafr Elshikh University, Egypt

Sayed Bakry, Ph D

Alazhar University, Egypt

Sameh Ali, Ph D

Nationa Liver Institute, Egypt

Gamal Badr, Ph D

Assuit University, Egypt

Nadia Hamdy, Pharm D

Ain Shams University, Egypt

\section{Editorial Board}

\section{Clinical studies}

Hesham Tawfik, MD

Tanta University, Egypt

Mohamed Attia, MD

Tanta University, Egypt

Mohamed Elshanshory, MD

Tanta University, Egypt

Essam Elshiekh, MD

Tanta Cancer Center, Egypt

Rasha Eraky, MD

Tanta University, Egypt

Shaima Abou-Kjatwa, MD

Tanta University, Egypt

Marcela Diaz, MD

Cleveland Clinic Foundation, USA

Mohamed Abou-El-Enein, MD

Charité Universitätsmedizin Berlin,

Germany
Alaa Eldin Almostafa, MD

McGill University, Canada

Olfat Gadallah, MD

Tanta University, Egypt

Nagla Sarhan, MD

Tanta University, Egypt

Naglaa Fathy, Pharm D

Zagazik University, Egypt

Mohamed Salama, MD

Mansoura University, Egypt

Mona Marie, MD

Alexandria University, Egypt

Preclinical studies

Mostafa El-Sheekh

Tanta University, Egypt

El-Refai Kenawy, Ph D

Tanta University, Egypt

Mohamed Noureldin, Ph D

Banaha University, Egypt

Yousry Albolkiny, Ph D

Tanta University, Egypt

Elsayed Salim, Ph D

Tanta University, Egypt

Shengdian Wang, Ph D

Chinese Academy of Sciences,

China

Sabry El Naggar, Ph D

Tnata Univesity, Egypr

Faris Alenzi, Ph D

Prince Sattam bin Abdulaziz

University, KSA

Ibrahim El-Sayed, Ph D

Menoufia University, Egypt

Tarek Aboul-Fadl, Ph D

Assiut University, Egypt

Rabab Khairat, Ph D

National Research Center,

Giza, Egypt

Wael Lotfy, Ph D

Alexandria University, Egypt

Ashraf Tabll, Ph D

National Research Center, Egypt

Nahla Shoukry, Ph D

Suez University, Egypt
Medhat Eldenary, Ph D

Tanta University, Egypt

Azza Hasan, Ph D

Menufia University, Egypt

Nanees Gamal Eldin, Ph D

Tanta University, Egypt

Mohamed Mansour, UK

Sabbah Hammoury, Ph D

Alexandria Ayadi Almostaqba

Oncology Hospital, Egypt

Nehal Aboulfotoh, Ph D

Zewail City for Science and

Technology, Cairo, Egypt

Amir Elkhami, Ph D

Galaxo, San Francisco, USA

Ahmed Alzohairy, Ph D

Zagazi University, Egypt

Wgady Khalil, Ph D

National Research Center, Egypt

Amr Amin, Ph D

United Arab Emirates

University, UAE

AbdelRahman Zekri, Ph D

National Cancer Institute, Egypt

Hussein Khamis, Ph D

Alexandria University, Egypt

Magdy Mahfouz, Ph D

Kafr Elsheikh University, Egypt

Ehab Elbedewey, Ph D

Tanta University, Egypt

Abeer Badr, Ph D

Cairo University, Egypt

Mamdooh Ghoneum, Ph D

Charles Drew University of

Medicine \& Science, USA

Haiam Abou Elela, Ph D

National Institute of Oceanography and Fisherie, Egypt

Maha EL-Demellawi, Ph D City for Scientific Research \&

Technology Applications, Egypt

Desouky Abd-El-Haleem, Ph D

City for Scientific Research \&

Technology Applications, Egypt 